\title{
PRINCÍPIOS RUGGIE E A PROTEÇÃO DE DIREITOS HUMANOS DOS SERES NÃO HUMANOS
}

\author{
RUGGIE PRINCIPLES AND THE HUMAN RIGHTS PROTECTION OFNON- \\ HUMAN BEINGS
}

\author{
Elisaide Trevisam ${ }^{1}$ \\ Jessé Cruciol Junior ${ }^{2}$
}

\begin{abstract}
RESUMO
Diante da dignidade dos seres não humanos, os Princípios Ruggie, que servem como norte para que as empresas se debrucem perante a necessidade da implementação e proteção de direitos humanos, apresentam a necessidade de reconhecimento de que os animais, como seres sencientes, também são destinatários de proteção jurídica autônoma. Desse modo, a presente pesquisa tem o escopo de demonstrar que os Princípios Ruggie, quando aplicados, devem levar em consideração os interesses dos seres não humanos apontando-se as consequências daí advindas para empresas, indivíduos e estados. Para encontrar um resultado satisfatório, a presente pesquisa será de caráter descritivo e exploratório e utilizará fontes bibliográficas e documentais na busca de atingir os resultados esperados.
\end{abstract}

PALAVRAS-CHAVE: Princípios Ruggie; Direitos humanos; Seres não humanos.

\begin{abstract}
Facing the dignity of non-human beings, the Ruggie Principles, which serves as a guide for companies that eliminates the needs for implementation and protection of human rights, presents the need for recognition that animals, as sentient beings, are also receiver of autonomous legal protection. Thus, the present research aims to demonstrate that the Ruggie Principles, when applied, must take into consideration the interests of non-human beings, pointing out the consequences arising from that for companies, individuals and states. In order to find a satisfactory result, this research will be descriptive and exploratory and will use bibliographic and documentary sources in order to achieve the expected results.
\end{abstract}

KEYWORDS: Ruggie principles; Human rights; Non-human beings.

1 Doutora em Filosofia do Direito pela Pontifícia Universidade Católica de São Paulo. Mestre em Direitos Humanos. Especialista em Direito do Trabalho e Processo do Trabalho. Professora no PPGD da Universidade Federal de Mato Grosso do Sul (UFMS).

2 Mestrando no Programa de Mestrado em Direito da Universidade Federal de Mato Grosso do Sul (UFMS). Juiz de Direito do Estado de Mato Grosso do Sul. 


\section{INTRODUÇÃO}

Os Princípios Orientadores sobre empresas e direitos humanos, aprovados pelo Conselho de Direitos Humanos das Nações Unidas no ano de 2011 (princípios Ruggie), pretendem ser um guia para empresas e atividades econômicas no que concerne à implementação e proteção de direitos humanos e reparação em caso de violação.

Por outro lado, tradicionalmente a noção de direitos humanos se ligava exclusivamente aos seres humanos, porém, há algum tempo vem-se reconhecendo, por motivos e fundamentos diversos, a dignidade própria dos animais e da natureza como um todo, de modo que sejam também destinatários de proteção jurídica autônoma, o que inclusive já foi albergado em textos constitucionais einternacionais.

Atualmente, há diversas correntes que vem reconhecendo a dignidade própria e independente dos seres não humanos (biocentrismo, ecocentrismo, senscientismo, etc), que tem em comum a negação da condição dos seres humanos como únicos dotados de dignidade a merecer consideração. O crescimento dessas correntes de pensamento vem influenciando os sistemas jurídicos, socioambientais e econômicos.

Em razão disso, a presente pesquisa tem como objetivo trazer uma breve análise dessas correntes, retirando o que delas há em comum e relacionando-as aos princípios Ruggie, que representam um padrão de conduta para empresas e estados no que concerne ao exercício de atividades econômicas com vistas à implementação de direitos humanos.

Após analisar os princípios Ruggie e as correntes que tratam da dignidade dos seres não humanos e da consideração de seus interesses, pretende-se demonstrar, ainda, que esses Princípios Orientadores (Ruggie) devem levar em consideração em sua interpretação e aplicação os interesses dos seres não humanos, em especial os animais, por sua senciência, apontando-se ainda consequências concretas daí advindas para empresas, indivíduos e estados.

Com o escopo de encontrar um resultado que satisfaça as perspectivas da presente pesquisa, foi utilizado uma metodologia de caráter exploratório utilizando-se de fontes bibliográficas e documentais.

Assim, reconhecendo-se os seres não humanos como destinatários de direitos humanos em sua relação com os humanos, os princípios Ruggie devem ser 
aplicados e considerados também como guia para proteção, implementação e reparação no que se refere aos direitos humanos dos seres não humanos, moldando e orientando a atividade empresarial.

\section{OS PRINCÍPIOS RUGGIE E SEU PAPEL NA ORDEM JURÍDICA, ECONÔMICA E SOCIOAMBIENTAL}

Em 16 de junho de 2011 o Conselho de Direitos Humanos da Organização das Nações Unidas aprovou, por meio de sua resolução 17/4, os "Princípios Orientadores sobre Empresas e Direitos Humanos: Implementando os Parâmetros de Proteger, Respeitar e Reparar das Nações Unidas", que são um conjunto de princípios orientadores globais para empresas concebidos para assegurar que estas não violem os direitos humanos no curso de suas operações e forneçam reparação quando da ocorrência de infrações". São os chamados "Princípio Ruggie".

Esse conjunto de princípios é assim denominado por terem sido criados por John Ruggie, sob comissão do então Secretário-Geral da Organização das Nações Unidas (ONU) Ban Ki-Moon. John Ruggie é professor da universidade americana de Harvard e foi nomeado Representante Especial do Secretário-Geral da ONU para a tarefa em 2005.

Em 2008, após três anos de intensas pesquisas e consultas com governos, empresas e sociedade civil em cinco continentes ${ }^{2}$, Ruggie apresentou o que seriam os três pilares (ou parâmetros, framework no original em inglês) dos Princípios Orientadores sobre Empresas e Direitos Humanos, quais sejam:

a) PROTEGER (protect): a obrigação dos Estados de proteger os direitos humanos contra abusos vindos de terceiros, incluindo empresas;

b) RESPEITAR (respect): a responsabilidade das empresas de respeitar os direitos humanos;

c) REPARAR (remedy): garantia de amplo acesso às vítimas a meios/remédios efetivos, tanto judiciais quanto extrajudiciais, em caso de violação.

1 Disponível em: https://nacoesunidas.org/conselho-de-direitos-humanos-aprova-principiosorientadores-para-empresas/. Acesso em: 21 out. 2019.

2 Disponível em: https://www.business-humanrights.org/sites/default/files/reports-andmaterials/Ruggie-protect-respect-remedy-framework.pdf. Acesso em 21 de out. de 2019. 
Esses parâmetros (framework) foram aceitos unanimemente pelo Conselho de Direitos Humanos. Além disso, o mandato do representante especial foi estendido por mais três anos com a finalidade de "operacionalizar" e "promover" os parâmetros ${ }^{3}$.

Ao final desse período, em junho de 2011 e, seguindo-se um período de consulta entre novembro de 2010 e janeiro de $2011^{4}$, foram apresentadosos 11 Princípios Orientadores sobre Empresas e Direitos Humanos pelo representante Especial John Ruggie, endossados pelo Conselho de Direitos Humanos, como já dito. Do ponto de vista jurídico é certo que os Princípios Orientadores não são considerados norma jurídica, isto é, vinculante, pois não tem a forma jurídica de Tratado ou Convenção na seara internacional. Trata-se de um documento expedido no âmbito da - e pela própria - Organização das Nações Unidas, mais especificamente pelo seu Conselho de Direitos Humanos, e que, portanto, tem força de uma recomendação (soft law), ou seja, tem caráter ético dissuasório.

Como seu próprio nome sugere trata-se de um guia para estados e empresas, esperando-se que os primeiros editem leis e regulamentos nesse sentido e que, juntamente com as segundas, deem cumprimento a esses princípios, respeitando e protegendo os direitos humanos em nome próprio e na relação com demais órgãos, pessoas e entidades, além de implementar meios de queixa e reparação no caso de violações de direitos humanos levadas ao seu conhecimento.

É importante notar que os Princípios Orientadores não estabelecem, fixam ou declaram direitos humanos em si, mas sim fixam diretrizes de conduta das empresas e estados em relação aos direitos humanos reconhecidos no que tange às suas atividades e negócios, quase como um "código" mínimo de conduta. Quanto a isso, aliás, o princípio 11 deixa claro que o documento se refere a todos os direitos humanos reconhecidos internacionalmente, dando, no entanto, ênfase a duas fontes formais específicas, in verbis:

\footnotetext{
3 Disponível em: https://www.business-humanrights.org/sites/default/files/reports-andmaterials/Ruggie-protect-respect-remedy-framework.pdf. Acesso em: 21 out. 2019.

4 Disponível em: https://www.business-humanrights.org/en/un-secretary-generals-specialrepresentative-on-business-human-rights/un-protect-respect-and-remedy-framework-and-guidingprinciples. Acesso em: 21 out. 2019.

5 Segundo o Institut de Droit International seriam textos adotados pelos sujeitos de direito internacional adotam que, apesar de gerarem obrigações em suas relações mútuas, são desprovidos, pela vontade expressa ou tácita das partes, de caráter jurídico (Mazzuoli, 2015, p. 181). Ainda segundo Mazzuoli (2015, p. 186), o que difere a soft law das demais normas seria o fato de ser ela um produto jurídico inacabado, voltada a assunção de compromissos futuros e de ser regida por um sistema de sanções distinto do tradicional, sendo seu cumprimento mais uma recomendação que uma obrigação.
} 
Princípio 11. A responsabilidade das empresas de respeitar os direitos humanos refere-se aos direitos humanos internacionalmente reconhecidos que incluem, no mínimo, os direitos enunciados na Carta Internacional de Direitos Humanos e os princípios relativos aos direitos fundamentais estabelecidos na Declaração da Organização Internacional do Trabalho relativa aos princípios e direitos fundamentais no trabalho.

Ainda, isso resta reforçado com o que consta nos "princípios gerais" constantes do próprio documento da ONU - no original em inglês ${ }^{6}$ - onde está estabelecido que não se deve entender aquele documento como criando novas obrigações de direitos internacional ou [ao contrário] mesmo limitando ou fragilizando qualquer obrigação que um Estado possa estar encarregado ou sujeito sob a legislação internacional no que concerne a direitos humanos.

Logo, qualquer direito humano internacionalmente reconhecido deve ser objeto de atenção e observância pelas empresas e Estados (proteção, respeito e reparação) na forma dos princípios Ruggie. Esse ponto será retomado mais à frente para os fins desse artigo.

Além disso, ainda sob esse título de princípios gerais é dito que os Princípios Orientadores se aplicam a todos os Estados e empreendimentos, transnacionais ou não, independente de tamanho, setor, localização, titularidade ou estrutura. Com isso, buscou-se ampliar ao máximo o alcance dos Princípios, de modo a serem vistos como verdadeiras regras gerais no exercício de qualquer atividade empresarial.

Para sua boa interpretação, também, fez-se constar que os Princípios Orientadores devem ser entendido como um todo coerente - evoca-se aqui a técnica da interpretação sistemática - e deve ser lido, individual ou coletivamente, no sentido do objetivo de ampliar padrões e práticas com relação a negócios e direitos humanos, de maneira a alcançar resultados tangíveis para indivíduos e comunidades afetados (mandamento de eficácia) e por isso, também, contribuindo para uma globalização socialmente sustentável.

Por fim, também estabelece que o documento deve ser implementado de forma não discriminatória, com particular atenção para os indivíduos de grupos ou populações com grande risco de se tornar vulneráveis ou marginalizados, além de atenção aos diferentes riscos enfrentados por homens e mulheres - aqui estabeleceuse o dever de observar as questões de gênero envolvidas nas atividades empresariais.

6 Disponível em: https://www.ohchr.org/documents/publications/GuidingprinciplesBusinesshr_eN.pdf. Acesso em: 21 out. 2019. 
Dito isso, é preciso explorar o grau de legitimidade e aplicabilidade dos princípios Ruggie às empresas privadas, cujo papel principal, até então reconhecido, era o de obter lucro, deixando para os Estados a função de distribuir justiça e reduzir desigualdades.

Segundo Vladmir Oliveira da Silveira e Samyra H. D. F. N. (2015, p. 117) Sanches, a terceira geração (ou dimensão) de direitos humanos, ligada ao princípio de solidariedade, levou a um redesenho do papel dos particulares na proteção de direitos humanos. Segundo os autores:

Os direitos de solidariedade, não só relativizam a soberania dos Estados, mas comprometem com a pauta de direitos, além do poder público, também o sujeito particular, as empresas e a coletividade. Por essa razão são chamados direitos de solidariedade, uma vez que expressam necessidades e anseios comuns a toda humanidade, cuja concretização depende da ação de todos.

Assim é que os direitos ligados à solidariedade impõem aos particulares pessoas ou empresas - condutas voltadas ao cuidado mínimo com o próximo, com o meio ambiente, os seres não humanos etc. Esse conjunto de direitos de terceira geração (ou dimensão) tem como principais pontos os direitos à paz, ao meio ambiente equilibrado, à autodeterminação dos povos, entre outros.

Já não basta mais que os particulares entreguem ao estado a responsabilidade por diminuir a desigualdade, sendo seu dever solidário, a par do lucro que retira, colaborar para que sua atividade seja fonte de soluções e bem estar e não de poluição, miséria, vício, violência etc.

Ainda, segundo Vladmir Silveira e Samyra Sanches (2015, p. 122), essa funcionalização da empresa importa no seguinte:

Assim, assumindo a empresa atividades historicamente estatais e não
sendo possível o retrocesso social, evidentemente à luz da eficácia
horizontal dos direitos humanos, é perfeitamente cabível em dadas
situações a exigência de que parte do lucro da atividade empresarial
tenha emprego no atendimento dos direitos sociais, procedendo-se à
melhor distribuição de riqueza e permitindo o desenvolvimento
humano.

Destarte, nessa quadra da história, considerando os avanços não só tecnológicos e jurídicos, mas também humanos, é de se esperar, com convicção de obrigatoriedade - quando não efetivamente positivado em legislação vinculante -, que os particulares, em especial as empresas, por sua enorme capacidade de ação e mobilização, ajam de forma solidária também no exercício de suas funções próprias, buscando o lucro de forma responsável e humana, sem que disso se faça fonte de 
miséria, extrema desigualdade, violência etc., mas, ao contrário, de bem-estar, sustentabilidade e responsabilidade para com o meio ambiente e com a sociedade como um todo.

Firmes nessa premissa, passamos agora a avaliar a questão dos direitos humanos dos seres não humanos, o que ao final, será relacionado ao que se discutiu nessa primeira parte.

\section{DIREITOS HUMANOS DOS SERES NÃO HUMANOS}

A evolução que será aqui analisada em razão do escopo da presente pesquisa será restrita à consideração humana diante dos demais animais, não obstante se possa dizer que, em linhas gerais, o raciocínio se aplique a toda a natureza, como se verá na apresentação das principais linhas de pensamento.

Iniciando-se a análise já a partir da era moderna - pois é desnecessária maior retroação histórica para os fins da presente pesquisa -, o desenvolvimento tecnológico, econômico e político que propiciou a revolução industrial foi apoiado em certos pressupostos ideológicos e científicos, dentre eles a concepção mecanicista cartesiana e newtoniana (CAPRA; MATTEI, 2018) que levou a um modelo extrativista e assumidamente antropológico, esse também cultivado no bojo do pensamento iluminista, o qual passou a prevalecer naquele momento histórico.

Desde concepções religiosas antigas prevalecentes no ocidente até as reflexões iluministas, todas centravam o mundo e seu sentido na figura humana. $O$ texto religioso judaico-cristão do velho testamento no livro de Gênesis, 1:28, já fazia constar: "Frutificai e multiplicai-vos, e enchei a terra, e sujeitai-a; e dominai sobre os peixes do mar e sobre as aves do céus, e sobre todo animal que se move sobre a terra" (grifos do autor).

Do mesmo modo a Declaração Universal dos Direitos do Homem e do Cidadão feita no contexto da revolução francesa é clara e expressamente antropocentrista.

Além disso, a doutrina de Immanuel Kant, que influenciou sobremaneira o pensamento ocidental daquela época, e que até hoje ainda é bastante influente, digase, também parte de um pressuposto antropocentrista, construindo sua noção de dignidade da pessoa humana, utilizada ainda hoje, sob a base de que as pessoas (o ser humano) não podem ser tratadas ou utilizadas como meio para qualquer fim, 
senão como um fim em si. Por outro lado, os animais seriam coisas e, em razão disso, não teríamos obrigações imediatas para com eles senão de forma indireta com a humanidade (JAMIESON, 2010, p. 151).

Porém, como esclarecido por Dale Jamieson (2010, p. 151), não se pode atribuir à Kant a tolerância com a maldade para com os animais, já que se pode coletar de seus escritos uma longa lista de deveres que se possui com relação aos animais, embora não diretamente com eles, dentre esses, o de que animais não devem ser mortos por esporte, não devem ser sobrecarregados de trabalho etc.

Ocorre que, quanto a essa visão antropocêntrica, como bem sintetizaram Ingo Sarlet e Thiago Fenterseifer, "a reflexão em torno da dimensão ecológica do princípio da dignidade da pessoa humana também coloca em 'cheque' a concepção estritamente antropocêntrica do Estado Constitucional." (SARLET; FENSTERSEIFER, 2017, p. 71). Assim, o passar do tempo e o avanço da técnica e do pensamento fez fragilizar os pressupostos da teoria predominante.

Com isso, o antropocentrismo vem sofrendo duros golpes de várias correntes de pensamento e ramos da ciência, dando conta da maior proximidade entre o homem e os demais animais do que se apregoava. Basta ver, por exemplo, que as pesquisas genéticas provaram a enorme proximidade genética entre o homem e diversos animais, como bonobos, chimpanzés e ratos ${ }^{7}$, pondo abaixo a supremacia do homo sapiens do ponto de vista biológico. Do mesmo modo, a capacidade intelectual e criativa dos golfinhos ${ }^{8}$ mostra que a psiquê dos animais não humanos é muito mais complexa do que se pensava.

Dentre os principais ataques teóricos ao antropocentrismo e à relegação dos demais animais a categoria de simples coisas com autopropulsão (semoventes na linguagem legal brasileira) destacam-se algumas. Martha Nussbaun (Apud SARLET; FENSTERSEIFER, 2017, p. 71), por exemplo, afirma que:

o reconhecimento da dignidade de determinadas existências não humanas implica uma questão básica de justiça, já que, na esteira do que foi afirmado por Aristóteles, há algo de admirável ou respeitável (Wonder-ful; WonderInspiring) em todas as formas complexas de vida animal.

7 Disponível em :http://revistaquem.globo.com/Revista/Quem/0,,EMl19189-9511,00COMPARACAO+DE+DNA+MOSTRA+QUE+SER+HUMANO+ESTA+MAIS+PARA+RATO+QUE+PAR A+GATO.html. Acesso em: 26 out. 2019.

8 Disponível em: https://super.abril.com.br/ciencia/a-verdadeira-inteligencia-dos-golfinhos/. Acesso em: 26 out. 2019. 
Desse modo rejeita a ideia de compaixão e humanidade no tratamento dos animais "defendendo uma ideia de justiça que transcenda essa perspectiva limitada para reconhecer o valor intrínseco e a dignidade de animais não humanos." (SARLET; FENSTERSEIFER, 2017, p. 71).

Esse mesmo "valor intrínseco" para além da esfera humana, ou seja, para todas as formas de vida que habitam a terra" (SARLET; FENSTERSEIFER, 2017, p. 75), buscou estabelecer o norueguês Arne Naess, que escreveu o pinacular livro Deep Ecology (Ecologia Profunda). Para ele, o valor das formas de vida não humanas independe de sua utilidade para os propósitos humanos (SARLET; FENSTERSEIFER, 2017, p. 75), com o que propõe o rompimento com o antropocentrismo clássico e a visão instrumental da natureza até então dominante.

Outro pensador a se debruçar sobre o tema foi o alemão Hans Jonas. Jonas estabelece a ligação básica entre natureza e humanidade, aquela enquanto suporte fático dessa, de modo que reflexivamente, a degradação da natureza impede o florescimento da vida digna (como condição sine qua non). Portanto "o futuro da humanidade é o primeiro dever do comportamento coletivo humano na idade da civilização técnica, que se tornou 'todo-poderosa' no que tange ao seu potencial de destruição" (JONAS, 2006, p. 229).

Vai ainda mais longe a responsabilidade do homem sobre toda a natureza invocada por Jonas (2006, p. 229):

\begin{abstract}
Mesmo que fosse possível separar as duas coisas - ou seja, mesmo que em um meio ambiente degradado (e em grande parte substituído por artefatos) fosse possível aos nossos descendentes uma vida digna de ser chamada humana, mesmo assim a plenitude da vida produzida durante o longo trabalho criativo da natureza e agora entregue em nossas mãos teria direito de reclamar nossa proteção.
\end{abstract}

Outrossim, Jonas (2006, p. 210) afirma que a solidariedade de destino entre homem e natureza, descoberta há pouco diante dos avanços que fizeram o homem ser capaz de destruir a natureza e a vida, "nos permite descobrir novamente a dignidade própria da natureza, conclamando-nos a defender os seus interesses para além dos aspectos utilitários".

Nesse momento, insta apontar que a consideração do ser humano como superior ou figura central (antropocentrismo) caracteriza o chamado especismo ou especiesismo. Este, nas palavras de Dalie Jamieson (2010, p. 181) "fornece a explicação pela difusão de nossa cegueira moral com respeito ao tratamento dos animais". 
Disso, especificamente quanto à relação com os demais animais, adviria que muitas de nossas práticas - danosas, violentas ou indiferentes - persistiriam somente porque não damos igual consideração aos interesses dos animais.

A propósito, o princípio da igualdade de consideração de interesses, segundo o qual a significância de um interesse não deve ser desprezada com base em "quem" tem o interesse, serviu de base para a teoria de Peter Singer sobre igualdade de consideração dos interesses das espécies. Para ele ainda, a igualdade que deve ser considerada entre as espécies não é a fatual, mas a moral (JAMIESON, 2010, p. 180).

Assim é que o estado atual do desenvolvimento coletivo, das ciências e, de um modo geral, do pensamento, impõem novas formas de se considerar o mundo e a relação do homem com o meio. Não à toa legislações nacionais e internacionais vêm trazendo disposições nesse sentido e com esse desiderato.

Com efeito, a Convenção sobre a Diversidade Biológica, de 1992, traz em seu preâmbulo o reconhecimento do valor intrínseco da diversidade biológica e dos valores ecológico, genético, social, econômico, científico, educacional, cultural, recreativo e estético da diversidade biológica e de seus componentes.

Outrossim, do ponto de vista das constituições nacionais, destacam-se três casos.

A Constituição equatoriana de 2008, nos capítulos 71 e seguintes estabelece a natureza ou Pacha Mama como sujeito de direitos, contrariando a noção tradicional de que apenas pessoas (seres humanos) tem direitos.

Do mesmo modo, a Constituição boliviana, em seu artigo 11, estabelece que as pessoas têm direito a um meio ambiente saudável, protegido e equilibrado. $O$ exercício desse direito deve permitir aos indivíduos e coletividade das presentes e das futuras gerações, além de outros seres vivos desenvolver-se de maneira normal e permanente. A expressão "outros seres vivos" não deixa muita dúvida que confere direitos à natureza (tudo o que tem vida nela, isto é, animais, vegetais, algas, bactérias etc.).

Por sua vez, a Constituição Federal brasileira apresenta peculiar redação em seu art. 225, inciso VII pois, logo após enunciar que cabe ao poder público e coletividade (caput) proteger a fauna e a flora, vedando - na forma da lei - as práticas que coloquem em risco sua função ecológica e provoquem a extinção de espécies, também veda, expressa e especificamente, práticas que submetam os animais à crueldade. 
Com isso, para além de se ater à tradicional ótica antropocentrista ingressouse no âmbito biocentrista, protegendo a dignidade dos animais por si só, já que "o bem estar dos animais nada tem a ver com a função ecológica por eles desempenhada" (RODRIGUES, 2019, p. 116)

É preciso também citar que, para além da lógica biocentrista, que recebe também importantes críticas ${ }^{9}$, há também a ótica ecocentrista, segundo a qual o que deve ser objeto de consideração moral não são os seres vivos (animais, vegetais, fungos, etc) em si, mas a "comunidade biótica" ou os ecossistemas (JAMIESON, 2010, p. 211).

Essa visão, crítica ao biocentrismo, enfatiza a importância da relação entre o meio e seus componentes por si só. Porém, também enfrenta severas críticas. Além da dificuldade de se identificar propriamente um ecossistema e quais seriam seus interesses, ainda é de se ponderar que a consideração sobre os interesses de um ecossistema é diferente dos interesses dos indivíduos que o compõem, subordinando esses aos seus próprios. Logo, a morte de indivíduos para preservar outros ou mesmo um outro interesse diverso do sistema em si seria plenamente admissível. Não por acaso, segundo Jamieson (2010, p. 216) Tom Reagan chamaria essa visão de "fascismo ambiental".

Exatamente em razão de questões como essa é que a visão ecocêntrica é de aceitação bastante restrita.

Em prosseguimento, e retomando o que foi até aqui explicitado, independente do apego à ótica biocêntrica, da defesa da proteção dos animais pela tradicional ótica antropocêntrica (Kant) ou mesmo de outra corrente de pensamento quanto aos interesses não humanos (sencientismo, etc), o fato é que a consideração das atividades humanas em geral e seus efeitos, em relação à natureza, vem tomando dimensão e rumos próprios.

No que tange aos animais, de simples coisa servil (objeto, instrumento da atividade e bem-estar humanos) agora são vistos como seres sencientes, dignos de respeito e cuidado, quando não de igual consideração com os humanos ${ }^{10}$.

9 Cf. explica JAMIESON, Dale na obra "Ética e meio ambiente: uma introdução", de 2010.

10 Não custa exemplificar com as lides concretas que discutem guarda/custódia e direito de visita em relação a animais domésticos em caso de divórcio ou rompimento de união estável de seus tutores. Disponível em: https://www.migalhas.com.br/Quentes/17,MI299601,51045Apos+divorcio+exconjuges+ficarao+cada+um+com+a+guarda+de+um+cao. Acesso: 26 out. 2019. 
Destarte, a relação dos humanos com os seres não humanos, em especial os animais, vem passando por profunda transformação (ainda em curso) o que já produz alguns efeitos nas ordens econômica, política e jurídica. Porém, há ainda muito o que fazer para que os animais tenham reconhecido o igual direito de consideração ou ao menos o de condição privilegiada na consideração de seus interesses enquanto seres sencientes e deveras próximos dos humanos do ponto de vista biológico.

Com isso, não se pode mais admitir qualquer tratamento cruel e degradante para com os animais (humanos e não humanos). Isso porque sendo o homem responsável pela natureza e pelo destino de todas as espécies, diante de sua enorme capacidade de criação, modificação e destruição (JONAS, 2006, p. 229) é certo que o exercício dessa responsabilidade importa em dispensar tratamento adequado, decente, em suma, "humano", aos animais em todas suas atividades (inclusive econômicas).

As competições animais dentro do espectro da cadeia alimentar ou da disputa por território ou acasalamento são naturais e decorrem de sua própria natureza, obedecendo a leis naturais inevitáveis. Não obstante, o comportamento humano é ou deve ser - primordialmente finalístico, orientado para certo fim, portanto. Diante disso, os meios para alcançar esse fim são escolhidos e perpetrados de acordo com o itinerário elegido e determinado.

Em razão disso, é coisa muito diversa que um animal ataque e, por hipótese, mate outro para se defender, alimentar, tomar território ou parceiro de acasalamento e que, por outro lado, um humano ataque outro animal, excetuada a hipótese de autodefesa quando isso não foi possível por outra forma.

O que se pretende dizer é que atualmente há plenas condições de se entender que, diante da estrutura da ação humana, o ataque aos animais sem ânimo inafastável de defesa, sua submissão a tratamento cruel ou degradante ou mesmo a omissão no trato minimamente adequado quando o animal não o possa fazer por si mesmo (por ser domesticado e afastado dos seus instintos, estar preso, debilitado, ferido etc.), e isso não importe em risco à própria vida ou saúde, é injustificável por leis naturais de conduta e ainda fere a responsabilidade humana para com o meio (JONAS, 2006). Acrescenta-se, ainda, o dever de solidariedade e consideração para com seres que também são sencientes, isto é, sentem dor, prazer, fome, medo etc.

Assim é que, mesmo sob diferentes visões e pressupostos teóricos ou filosóficos, os animais e a natureza em geral (como já reconhecem algumas 
Constituições) tem direitos mínimos de tratamento e consideração a serem observados pelos humanos (únicos que se sabe agir responsavelmente de forma finalística e não predominantemente guiada por instintos básicos).

Por fim, é preciso esclarecer ainda quanto aos direitos - ou pretensão de direitos - dos animais que estão previstos no documento da UNESCO denominado Declaração Universal dos Direitos dos Animais ${ }^{11}$. Essa declaração, apesar de difundida, não tem efeito jurídico no âmbito do Direito Internacional. Contudo, seus termos, por bastante consentâneos com o pensamento atual sobre a consideração para com os animais e sua relação com os humanos e suas atividades, pode ser utilizada como parâmetro ético para ações, planos, políticas e legislações.

Com isso, fica bem delineada a nova forma como é (ou deve ser) vista a relação entre seres humanos e não humanos, além de sua inextricável ligação recíproca (solidariedade de destino nas palavras de Hans Jonas). Portanto, o tratamento formal e material dado aos seres não humanos merece ser repensado em várias frontes, inclusive no que tange ao exercício de atividades econômicas, pois não podem ser mais vistos com meros e insensíveis objetos a serviço do deleite humano.

\section{APLICABILIDADE DOS PRINCÍPIOS RUGGIE PARAOS SERES NÃO HUMANOS}

Os Princípios Orientadores (Ruggie), como foi aqui exposto, são guias para a conduta ética das empresas e negócios em geral para respeitar, proteger e reparar direitos humanos. Através deles espera-se que as empresas, grandes atores na vida social, econômica, laboral etc., da humanidade respeitem e façam respeitar os direitos humanos reconhecidos.

Pois bem. Se a consideração para com os animais impõe que estes tenham tratamento minimamente digno, é certo que lhes deve ser garantido o direito à vida, bem-estar, condições dignas de "trabalho" (quando são utilizados para tanto), tanto quanto o de não receber tratamento cruel e degradante, o que inclusive consta expressamente na Constituição Federal brasileira e pode ser inferido das Constituições equatoriana e boliviana, além da Convenção sobre a Diversidade Biológica de 1992.

\footnotetext{
11 Declaração proclamada em 1978 pela Liga Francesa de Direito Animal na sede da Unesco em Bruxelas. Disponível em:
droitanimal.org/rubriques/connaitr_fond/connaitr_fond.htm. http://www.fondation-
} 
O cerne dessa proteção é justamente coincidente, mutatis mutandis, com o que se define por direitos humanos. Estes, quando não definidos apenas pela tautologia (direitos humanos são atribuídos às pessoas somente por serem humanos) ou formalmente (direitos humanos são aqueles reconhecidos formalmente no âmbito do Direito internacional como tanto) são definidos por sua finalidade.

Nesse sentido muito bem coloca Jose Luiz Bolzan de Morais (apudOLIVEIRA, 2011, p. 181):

\begin{abstract}
Resumidamente poderíamos dizer, então, que os direitos humanos, como conjunto de valores históricos básicos e fundamentais, que dizem respeito à vida digna jurídico-político-psíquico-físicoeconômica e afetiva dos seres humanos e de seu habitat, tanto daqueles do presente quanto daqueles do porvir, surgem sempre como condição fundante da vida, impondo aos agentes político-jurídico-econômico-sociais a tarefa de agirem no sentido de permitir e viabilizar que a todos seja consignada a possibilidade de usufruílos em benefício próprio e comum ao mesmo tempo.
\end{abstract}

Logo, mesmo correndo o risco de recair no extensionismo moral ${ }^{12}$, a estrutura básica do que se reconhece como direitos humanos é aplicável aos animais não humanos, já que a eles se deve reconhecer direitos mínimos de vida e bem-estar e, como já positivado, por exemplo, na Constituição brasileira, garantia contra tratamento cruel e degradante.

Consequência disso é que os Princípios Ruggie devem ser aplicados também no que se refere ao bem-estar animal, lembrando que os Princípios orientadores não criam direitos mas fixam diretrizes de conduta das empresas e estados em relação aos direitos "humanos", no que se refere às suas atividades e negócios.

Portanto, os 11 Princípios Orientadores devem ser interpretados como abrangendo também os direitos de bem-estar animal, servindo de guia ético mínimo para empresas e estados nesse sentido.

Assim, pode-se apontar, desde logo, algumas consequências advindas disso. Em razão do contido no princípio 11 é dever das empresas - de qualquer tamanho, setor, contexto operacional, proprietário e estrutura (princípio 14) - respeitar os direitos humanos dos seres não humanos, abstendo-se de infringir os direitos humanos de terceiros e enfrentando os impactos negativos sobre os direitos humanos nos quais tenham algum envolvimento.

Assim, qualquer experimento ou método que cause sofrimento, danos à saúde ou risco aos animais, seu sustento ou habitat, devem ser evitados e abandonados e, 
acaso contingencialmente ocorridos, devidamente reparados. Desse modo, experimentos com animais e dissecações, por exemplo, devem ser substituídos por outros métodos, mormente agora, onde a tecnologia traz inúmeras possibilidades para suprir essa "necessidade" no desenvolvimento de produtos e facilidades.

O uso de partes de animais (pele, chifres, barbatanas etc.) também deve ser objeto de atenção de governos e empresas, pois é frequente causa de sofrimento, matança e até extinção de espécies.

Outrossim, devem as empresas (princípio 17) realizar auditorias para identificar, prevenir, mitigar e reparar os impactos negativos de suas atividades sobre os direitos humanos dos seres não humanos. Com isso, é preciso que o exercício dessa responsabilidade pelas empresas seja contínuo, sempre monitorando os impactos e métodos de sua atividade também para os animais (seres não humanos em geral).

As empresas devem se atentar também para violações em suas relações comerciais (princípio 18), buscando proteger e respeitar direitos dos seres não humanos quando realizarem (ou recusarem) relações comerciais com outras empresas, pessoas e governos.

Outrossim, a par de outros deveres das empresas e dos estados para proteção dos interesses dos seres não humanos nos negócios também é de se destacar a obrigação estatal (princípio 26) de adotar as medidas apropriadas para assegurar a eficácia dos mecanismos judiciais nacionais quando abordem as violações de direitos humanos [inclusive de não humanos] relacionadas com empresas, especialmente considerando a forma de limitar os obstáculos jurídicos, práticos e de outras naturezas que possam conduzir para uma negação do acesso aos mecanismos de reparação.

Por força disso, a jurisdição e a proteção administrativa devem estar abertas para a proteção de direitos dos seres não humanos no que tange às atividades empresariais, tanto quanto a atividade legislativa deve ser posta a trabalhar nesse sentido.

Em conclusão, fazendo-se as devidas adaptações (mutatis mutandis), os Princípios Ruggie, em geral, devem ser interpretados de modo a abranger todos os direitos humanos dos seres não humanos.

\section{CONSIDERAÇÕES FINAIS}


Os princípios Ruggie são princípios orientadores aprovados pelo Conselho de Direitos Humanos da Organização das Nações Unidas em 2011 para servir de guia à empresas e Estados objetivando, principalmente, que respeitem e protejam os direitos humanos em nome próprio e na relação com demais órgãos, pessoas e entidades, além de implementar meios de queixa e reparação em caso de violação desses direitos.

Tradicionalmente ligados aos direitos de seres humanos, os direitos humanos (e a consequente consideração digna) vem sendo cada vez mais entendidos como aplicáveis também aos seres não humanos, considerando o ocaso do antropocentrismo até então prevalecente, o reconhecimento da dignidade independente e autônoma dos animais e da natureza enquanto tais e, mesmo a solidariedade de destino entre homem e natureza, somado à responsabilidade diferenciada dos seres humanos dado seu atual poder de criação e destruição (inclusive de aniquilação da vida na terra).

Em razão do reconhecimento da dignidade própria dos seres não humanos, seus interesses devem ser levados em consideração nas atividades e políticas humanas, inclusive econômicas.

Com isso, sendo os princípios Ruggie atualmente o padrão do Conselho de Direitos Humanos da Organização das Nações Unidas para a implementação, proteção e reparação no que se refere a direitos humanos, devem eles ser interpretados como abrangendo também os direitos humanos dos seres não humanos, nomeadamente - para os fins desse artigo - dos animais, tornando-se padrão de conduta com relação aos seres não humanos em atividades econômicas e empresariais, buscando atingir para a efetivação de um meio ambiente sustentável, responsável e solidário.

\section{REFERÊNCIAS}

CAPRA, Fritjof; MATTEI, Ugo. A revolução Ecojurídica: o direito sistêmico em sintonia com a natureza e a comunidade. Tradução Jeferson Luiz Camargo. São Paulo: Editora Cultrix, 2018

CONECTAS DIREITOS HUMANOS. Empresas e Direitos Humanos: Parâmetros da ONU para Proteger, Respeitar e Reparar. Relatório Final de John Ruggie: Representante Especial do Secretário-Geral. Disponível em: 
https://www.socioambiental.org/sites/blog.socioambiental.org/files/nsa/arquivos/cone ctas_principiosorientadoresruggie_mar20121.pdf. Acesso em: 26 out. 2019.

JAMIESON, Dale. Ética e meio ambiente: uma introdução. Tradução de André Luiz de Alvarenga. São Paulo: Editora Senac, 2010.

JONAS, Hans; 0 princípio responsabilidade: ensaio de uma ética para a civilização tecnológica. Tradução Marijane Lisboa e Luiz Barros Montez. Rio de Janeiro: Contraponto, 2006.

MAZZUOLI, Valério de Oliveira. Curso de direito internacional público. 9. ed. rev. Atual. e ampl. São Paulo: Revista dos Tribunais, 2015.

OLIVEIRA, Saullo Pereira de. A supremacia dos direitos humanos universais perante a soberania de um estado arbitrário. Revista da Escola Superior da Magistratura do Estado do Ceará - ESMEC. Fortaleza, vol. 11, p. 175-192, 2011.

PORTO, Adriane Célia de Souza; PACCAGNELLA, Amanda Formisano. A verdadeira natureza jurídica da Declaração Universal dos Direitos dos Animais e sua força como carta de princípios. Revista Âmbito Jurídico. São Paulo, v. 165, out. 2017.

RODRIGUES, Marcelo Abelha. Direito ambiental esquematizado. 6. ed. São Paulo: Saraiva, 2019.

SARLET, Ingo Wolfgang; FENSTERSEIFER, Tiago. Princípios do direito ambiental. 2. ed. São Paulo: Saraiva, 2017.

SILVEIRA, Vladmir Oliveira da; SANCHES, Samyra Haydêe Dal Farra Naspolini. Direitos humanos, empresa e desenvolvimento sustentável. Revista Juridica, [S.I.], v. 1, n. 18, p. 111- 127, dez. 2015. ISSN 2116-751X. Disponível em: http://revista.unicuritiba.edu.br/index.php/RevJur/article/view/1422/965. Acesso em: 22 abr. 2020. doi:http://dx.doi.org/10.21902/revistajur.2116-751X.v1i18.1422.

UNITED NATIONS (UN). Office of The High Commissioner for Human Rights. Guiding Principles on Business and Human Rights. Disponível em: https://www.ohchr.org/documents/publications/GuidingprinciplesBusinesshr_eN.pdf. Acesso em: 21 out. 2019.

UNITED NATIONS (UN). Disponível em: https://www.businesshumanrights.org/sites/default/files/reports-and-materials/Ruggie-protect-respectremedy-framework.pdf. Acesso em: 21 out. 2019. 